\title{
CALCULATION OF CATALYTIC REACTIVITY FOR PREPARING DICHLORODIMETHYLSILANE UTILIZING PRE- AND POST-MODIFIED 24T AICl $/$ ZSM-5
}

\author{
Wenyuan Xua,*, Mei Yang ${ }^{\mathrm{a}}$, Xiaoyan Liª, Shaoming Yanga, Xi Chena, Zhili Fanga, Xiaoxin Wu ${ }^{\mathrm{a}}$, and Sanguo Hong \\ ${ }^{a}$ School of Material Science and Engineering, East China Jiaotong University, Nanchang, China \\ ${ }^{\mathrm{b}}$ College of Chemistry, Nanchang University, Nanchang, China
}

Recebido em 07/06/2017; aceito em 20/09/2017; publicado na web em 08/11/2017

\begin{abstract}
Dichlorodimethylsilane is the most important raw material for the preparation of organic silicon materials. Currently, the preparation of dichlorodimethylsilane is mainly based on disproportionation method. This method can turn wastes (by-products) into treasures but the mechanism is still indeterminate. In this study, MP2/6-311++G (3df, 2pd) basis set was used to study the mechanism of the disproportionation for producing dichlorodimethylsilane. Dichlorodimethylsilane is catalyzed by $24 \mathrm{~T}$ cluster $\mathrm{AlCl}_{3} / \mathrm{ZSM}-5$ catalyst and modified by $\left(\mathrm{AlCl}_{2}\right)^{+}$, and $\left(\mathrm{BCl}_{2}\right)^{+}$. The calculation results show that the rate-determining step is the reaction of the catalyst with trimethylchlorosilane. The activation energy of the rate-determining step of main reaction is: $393.83,427.73$, and $527.61 \mathrm{~kJ} \mathrm{~mol}^{-1}$, respectively. The structure analysis, activation energy analysis and LOL analysis for different catalysts all show that the catalytic effect of unmodified $\mathrm{AlCl}_{3} / \mathrm{ZSM}-5$ is better.
\end{abstract}

Keywords: 24T cluster; $\mathrm{AlCl}_{3} / \mathrm{ZSM}-5$; dichlorodimethylsilane; mechanism.

\section{INTRODUCTION}

Organic silicon is a class of materials containing C-Si bond, with at least one organic group directly connected to the silicon atoms. ${ }^{1}$ Due to its unique structure, organic silicon has been widely used in all aspects of industries, including construction, medical, automotive, and other fields. It is known as the "Industrial MSG" or "Industry Balm", ${ }^{2}$ as recently reported by Journal of Materials Science. ${ }^{3}$ The level of industrial silicone is determined by the production of its monomer, and dichlorodimethylsilane $\left(\left(\mathrm{CH}_{3}\right)_{2} \mathrm{SiCl}_{2}, \mathrm{M}_{2}\right)$ is the largest and most versatile organic silicon monomer. ${ }^{4,5}$ The disproportionation for producing dichlorodimethylsilane often uses methyltrichlorosilane $\left(\mathrm{CH}_{3} \mathrm{SiCl}_{3}\right.$, $\mathrm{M}_{1}$, waste) and trimethylchlorosilane $\left(\left(\mathrm{CH}_{3}\right)_{3} \mathrm{SiCl}, \mathrm{M}_{3}\right.$, waste $)$ as precursors. This method can turn the $\mathrm{M}_{1}$, and $\mathrm{M}_{3}$ waste into treasure. Thus, it is crucial to prepare $\mathrm{M}_{2}$ effectively and environmentally friendly. The crucial question of silane disproportionation ${ }^{6}$ is the choice of catalyst. Jingen Xue et al. ${ }^{7}$ studied the disproportionation for producing dichlorodimethylsilane by using $\mathrm{Al}_{2} \mathrm{O}_{3}$ and $\mathrm{AlCl}_{3}$ as catalysts, respectively. They found that the yields of dimethyldichlorosilane were $30 \%$ and $49.8 \%$, respectively. Jianbo Zhao et al. ${ }^{8}$ used organic amines and transition metals (more expensive) as catalysts, respectively. They found that the yields of dimethyldichlorosilane were $20.8 \%$ and $76.1 \%$, respectively. By comparison, $\mathrm{AlCl}_{3}{ }^{9-11}$ has good catalytic performance. But the reaction requires high temperature and pressure to occur, and it also has environmental protection. ${ }^{12}$ Although $\mathrm{AlCl}_{3}$ exhibits good catalytic activity, it requires the reaction environments of high temperature and high pressure. Because of its low sublimation temperature $\left(178^{\circ} \mathrm{C}\right),{ }^{13}$ so it is easy to cause loss when reacting at atmospheric pressure. To solve this problem, $\mathrm{AlCl}_{3}$ is loaded on the carrier to improve its sublimation temperature. ${ }^{14}$ As solid acid catalysts, $\mathrm{AlCl}_{3}$ and $\mathrm{AlCl}_{3} / \mathrm{ZSM}-5$ have demonstrated good catalytic effect both in the cracking of organosilicon high-boiling components and low-boiling-point substance. ${ }^{15-17}$ So far, most of the relevant studies are limited to experimental work, and the specific reaction

*e-mail: xwyktz@163.com process is not clear. The preliminary work in our laboratory showed that the surface of the $5 \mathrm{~T}$ cluster $\mathrm{AlCl}_{3} / \mathrm{ZSM}-5$ had good catalytic activity, ${ }^{18}$ and the active sites in the large pores were similar to those on the surface. In order to study the catalytic mechanism of the ZSM-5 comprehensively, the 24T cluster ZSM-5 model was selected. Studies reveal that $\mathrm{AlCl}_{3}$, and $\mathrm{BCl}_{3}{ }^{19}$ have good acidity, and provide Lewis acid. In addition, the active sites of $\mathrm{AlCl}_{3} / \mathrm{ZSM}-5$ are in the form of $\left(-\mathrm{AlCl}_{2}\right)$. To further explore the catalytic mechanism of the macroporous molecular sieve catalysts and examine the modification effect of $\left(\mathrm{AlCl}_{2}\right)^{+}$and $\left(\mathrm{BCl}_{2}\right)^{+}$, we also investigated the mechanism of the disproportionated reaction for producing dichlorodimethylsilane catalyzed by $24 \mathrm{~T}$ cluster $\mathrm{AlCl}_{3} / \mathrm{ZSM}-5$ (Cat. I), $\mathrm{AlCl}_{3} /\left(\mathrm{AlCl}_{2}\right)^{+}-\mathrm{ZSM}-5$ (Cat. II), and $\mathrm{AlCl}_{3} /\left(\mathrm{BCl}_{2}\right)^{+}-\mathrm{ZSM}-5$ (Cat. III). Finally, the catalytic substance of $\mathrm{AlCl}_{3} / \mathrm{ZSM}-5$ and modified by $\left(\mathrm{AlCl}_{2}\right)^{+}$, and $\left(\mathrm{BCl}_{2}\right)^{+}$was explained from the micro perspective.

\section{CALCULATION METHOD}

The paper applied Density Functional Theory (DFT) ${ }^{20-24}$ method of quantum chemistry to calculate the structures of the reactants, transition states, intermediates, and products at the B3LYP/6-31G level. In this paper, the transition states are searched by utilizing $\mathrm{TS}^{25,26}$ method. The calculation of vibration analysis shows that the imaginary frequency of all the reactants, intermediates, and products are positive frequency. Therefore, they are stable stationary points on the potential energy surface. All the transition states have only one negative imaginary frequency, indicating that the transition states are the saddle points on the potential energy surface. So transition state structures are credible. In order to confirm the validity of the reactants, transition states, and products, the analyses of vibrational and the internals reaction coordinate (IRC) were conducted. The energy of each structure was calculated using second-order MollerPlesset perturbation theory (at MP2/6-311++G (3df, 2pd) level), ${ }^{27}$ and the Zero Point Energy (ZPE) correction was also considered. Finally, LOL (localized-orbital locator) ${ }^{28,29}$ analysis of the three catalysts were carried out to compare their catalytic activity. The localizedorbital locator can not only analyze the problems of localization and delocalization, but also characterize the chemical bonds. In this 
paper, all the calculations have been completed by the Gaussian 09 (Gaussian Inc., Wallingford CT) ${ }^{30-33}$ program and the images have been drawn by using the Gaussian view, ChemDraw. ${ }^{34-36}$

\section{RESULTS AND DISCUSSION}

We first demonstrate our calculation results for the reaction mechanism of disproportionating methyltrichlorosilane and trimethylchlorosilane, which are catalyzed by $24 \mathrm{~T}$ cluster $\mathrm{AlCl}_{3} / \mathrm{X}-$ ZSM-5 (X stands for pre- and post-modified by $\left(\mathrm{AlCl}_{2}\right)^{+}$, and $\left.\left(\mathrm{BCl}_{2}\right)^{+}\right)$. The reaction formula is shown in Figure 1, and is divided into two channels. The first step of the disproportionate reaction is the forming process of the intermediate and dichlorodimethylsilane via transition state TS1 in channel 1 . In order to make the disproportionation proceed smoothly, the four key atoms $\left(\mathrm{Cl}^{3}-\mathrm{Si}^{2}\right.$ and $\mathrm{C}^{2}-\mathrm{Al}^{4}$ are close to each other, $\mathrm{Si}^{2}-\mathrm{C}^{1}$ and $\mathrm{Al}^{1}-\mathrm{Cl}^{4}$ are slightly away from) form the transitional state TS1 which is a four-membered ring structure. The bonds of four-membered ring structure are not fully formed and not completely broken. This is consistent with the results of the previous configuration. ${ }^{19}$ The transition states in the subsequent steps also have the similar four-membered ring structure. ${ }^{18} \mathrm{Next}$, the intermediate reacts with methyltrichlorosilane via transition state TS2. The catalyst and dichlorodimethylsilane are received by this reaction. This process is the main reaction, and is the main channel of the reaction. In channel 2 , the intermediate and by-product of silicon tetrachloride are gained through methyltrichlorosilane and catalyst reaction. The catalyst and by-product (silicon tetrachloride) are then received through trimethylchlorosilane and intermediate reaction. This process is the side reaction. The formulas of the two channels are shown in Figure 1, and the whole process is shown in Figure 2.

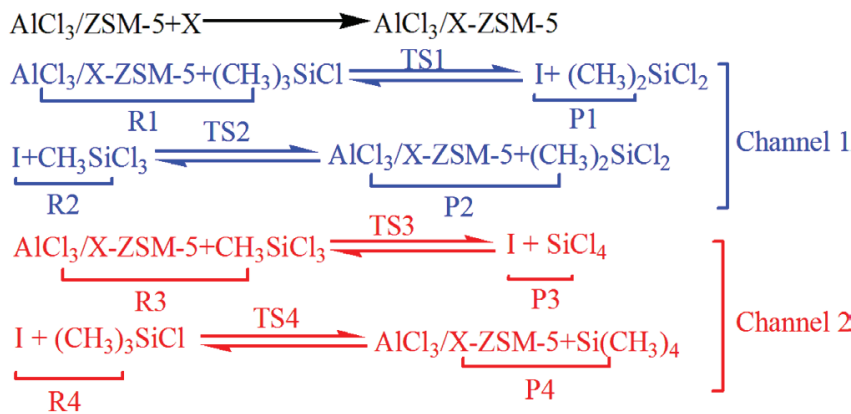

Figure 1. The formula of the catalytic process

The optimized geometric parameters (bond length, bond angle) are shown in table 1 . After modification, the bond angles are reduced, especially the bond angle $\left(\angle \mathrm{O}^{6}-\mathrm{Al}^{4}-\mathrm{O}^{7}\right)$ of active site. It shows that the pore of the catalyst is reduced, which is adverse for the larger trimethylchlorosilane to participate in reaction into the channel. It is found that the order of the bond length is: Cat. I > Cat. II > Cat. III by comparing the bond length $\left(\mathrm{Al}^{4}-\mathrm{Cl}^{3}\right)$ of active site. So the $\mathrm{Al}^{4}-\mathrm{Cl}^{3}$ bond of Cat. I is more easily broken and $\mathrm{Cl}$ is more likely to participate in disproportionation reaction, which is shown in Figure 2. In summary, it is indicated that the catalytic activity may decrease after modification.

In order to prove the authenticity of the transition state structure, the vibration frequency analysis of each transition state structure is carried out. The results of the analysis show that the structures of these transition states are valid, as shown in Figure 4
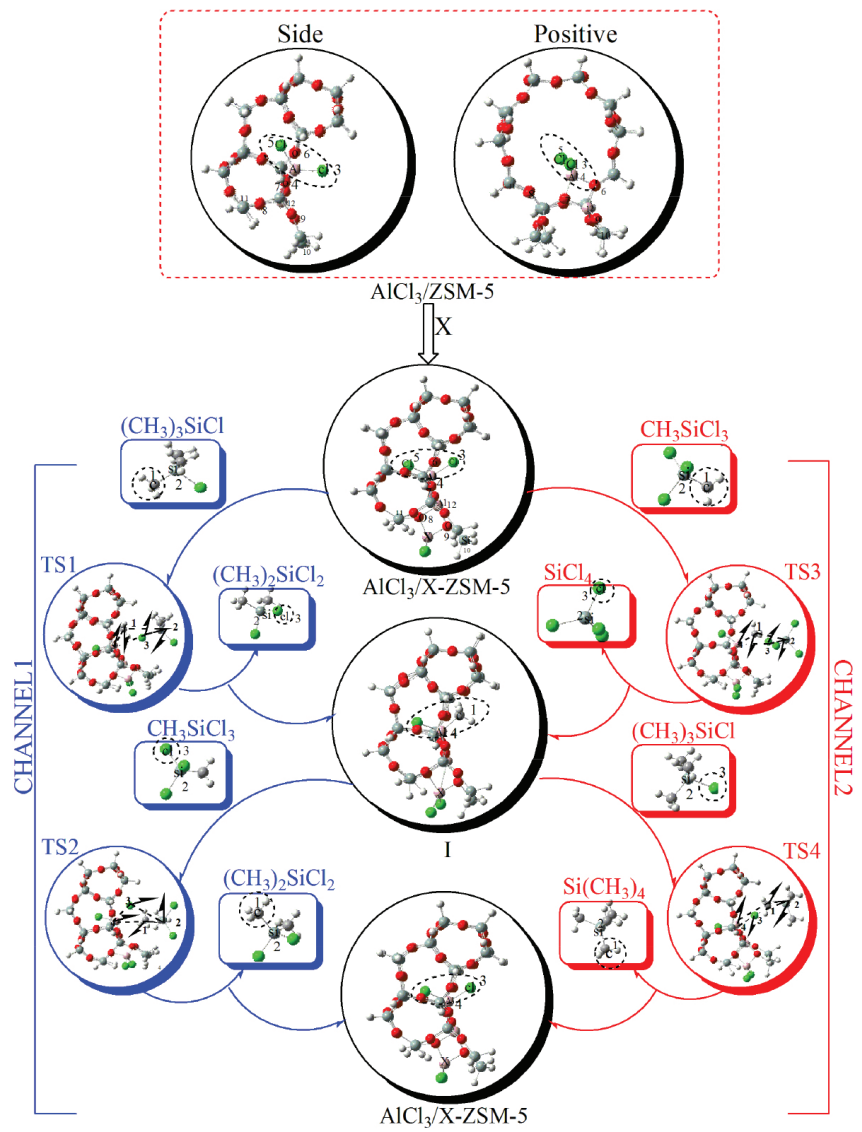

Figure 2. Molecular structures, key atomic number, reaction process, and the virtual vibration mode of transition states

Table 1. Optimized geometric parameters of $\mathrm{AlCl}_{3} / \mathrm{X}-\mathrm{ZSM}-5$ catalyst

\begin{tabular}{lcccc}
\hline & & $\mathrm{AlCl}_{3} / \mathrm{ZSM}-5$ & $\mathrm{AlCl}_{3} /\left(\mathrm{AlCl}_{2}\right)^{+}-\mathrm{ZSM}-5$ & $\mathrm{AlCl}_{3} /\left(\mathrm{BCl}_{2}\right)^{+}-\mathrm{ZSM}-5$ \\
\hline Bond length $(\mathrm{nm})$ & $\mathrm{Al}^{4}-\mathrm{Cl}^{5}$ & 0.22069 & 0.21675 & 0.21673 \\
& $\mathrm{Al}^{4}-\mathrm{Cl}^{3}$ & 0.22061 & 0.21674 & 0.21672 \\
& $\mathrm{Al}^{4}-\mathrm{O}^{6}$ & 0.18347 & 0.18543 & 0.18561 \\
& $\mathrm{Al}^{4}-\mathrm{O}^{7}$ & 0.18347 & 0.18551 & 0.18561 \\
& $\mathrm{X}-\mathrm{O}^{8}$ & - & 0.18551 & 0.15583 \\
& $\mathrm{X}-\mathrm{O}^{9}$ & - & 0.18543 & 0.15589 \\
& $\mathrm{O}^{8}-\mathrm{Si}^{10}$ & 0.17697 & 0.17831 \\
$\mathrm{O}^{9}-\mathrm{Si}^{11}$ & 0.16702 & 0.17698 & 0.17831 \\
\hline Bond angle $\left(^{\circ}\right)$ & $\angle \mathrm{O}^{6}-\mathrm{Al}^{4}-\mathrm{O}^{7}$ & 84.4823 & 82.3667 & 82.3295 \\
& $\angle \mathrm{O}^{8}-\mathrm{Al}^{12}-\mathrm{O}^{9}$ & 114.2429 & 86.4267 & 86.6915 \\
\hline
\end{tabular}


The transition states are tracked during calculation in Forward and Reverse using the IRC method. We take TS1 as an example, the $\mathrm{Cl}^{3}$ atom moves to the $\mathrm{Si}^{2}$ atom, and bonds with it when the catalyst takes part in the reaction. Meanwhile, the $\mathrm{Si}^{2}-\mathrm{C}^{1}$ bond and $\mathrm{Al}^{1}-\mathrm{Cl}^{4}$ bond are broken. The $\mathrm{C}^{2}$ and $\mathrm{Al}^{4}$ atoms gradually move close to each other, and bond to produce product P1 at the same time. Finally, the corresponding products are generated from reactants via TS1, which confirms the accuracy of the reaction path. The spacing traces of the key atoms along the IRC are calculated, as shown in Figure 3. The results show that the key atoms along the IRC path have the tendency to bond or break, and move towards their respective reactants or products, which proves that the mechanism is valid. Thus, it is proved that the reaction process (shown in Figure 1 and Figure 2) is reasonable.

The energy is calculated by using second-order Moller-Plesset perturbation theory (at MP2/6-311++G (3df, 2pd) level) and the Zero Point Energy (ZPE) correction is considered. The reaction enthalpies $(\Delta \mathrm{H})$ and activation energies $\left(\mathrm{E}_{\mathrm{a}}\right)$ are given in Table 2. The activation energies of $\mathrm{AlCl}_{3} / \mathrm{X}-\mathrm{ZSM}-5$ reaction system are shown in Figure 5. The activation energy of the rate-determining step in the main reaction is: $393.83,427.73$, and $527.61 \mathrm{~kJ} \mathrm{~mol}^{-1}$, respectively. The activation energy of the rate determining step of side reaction is: $461.43,483.62$, and $429.01 \mathrm{~kJ} \mathrm{~mol}^{-1}$, respectively. With regard to Cat. I and Cat. II, the activation energy of RDS in channel 1 is lower than channel 2, indicating that channel 1 is the main reaction. For Cat. III, although the activation energy of RDS in channel 2 is lower than channel 1 , its numerical value is large. So the reaction is
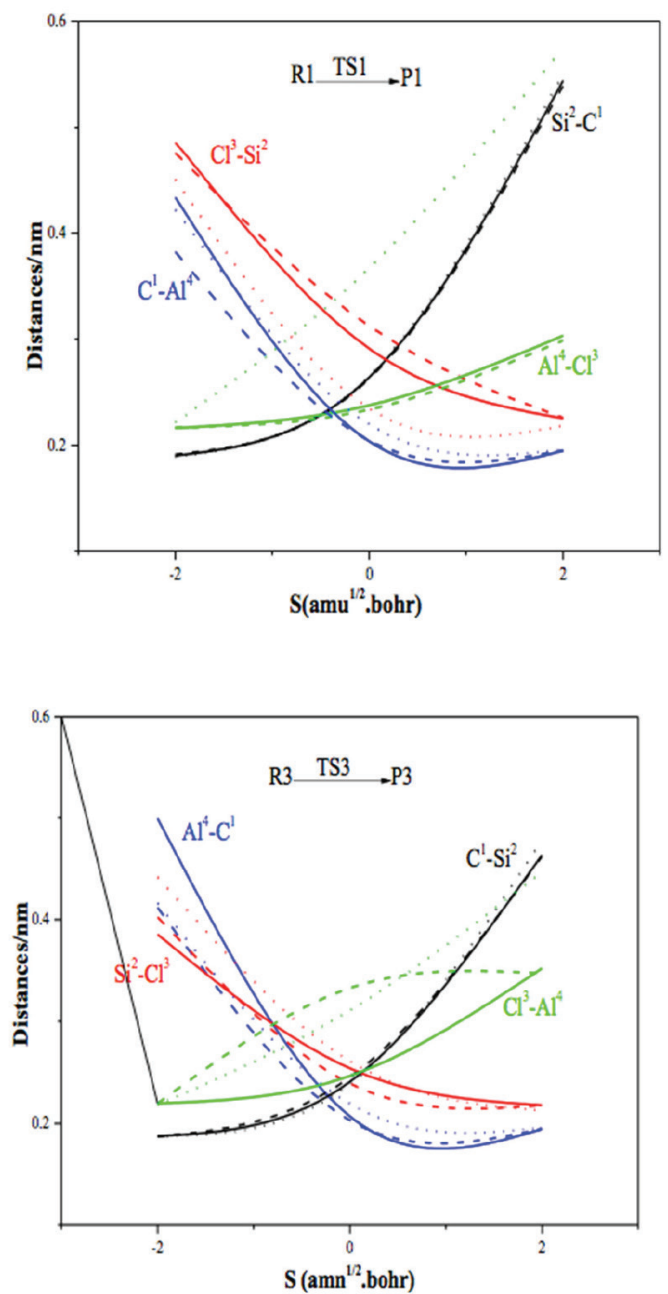

not easy to occur. It is further explained that the unmodified catalyst is effective. The activation energy of the main reaction for Cat. I $\left(393.83 \mathrm{~kJ} \mathrm{~mol}^{-1}\right)$ is lower than that of Cat. II $\left(427.73 \mathrm{~kJ} \mathrm{~mol}^{-1}\right)$ and Cat. III $\left(527.61 \mathrm{~kJ} \mathrm{~mol}^{-1}\right)$. The order of the activation energy is: Cat. I > Cat. II > Cat. III. Comparing with the 5 T cluster $\mathrm{AlCl}_{3} /$ ZSM-5 $\left(93 \mathrm{~kJ} \mathrm{~mol}^{-1}\right),{ }^{18}$ it is shown that $5 \mathrm{~T}$ cluster is better. This indicates that the main activity of the disproportionation reaction is on the surface of the catalyst. But, the $24 \mathrm{~T}$ catalytic system effect is not so ideal, and the catalytic effect of the unmodified catalyst is slightly better. The bond of Cat. I is easier to form, so the reaction is easier to occur. The catalyst of $\mathrm{AlCl}_{3} / \mathrm{ZSM}-5$ modified by $\left(\mathrm{AlCl}_{2}\right)^{+}$, and $\left(\mathrm{BCl}_{2}\right)^{+}$is ineffective, and the catalytic activity is obviously reduced. The reason may be that the electron cloud density of acid site $\left(-\mathrm{AlCl}_{2}\right)$ is reduced when modified by $\left(\mathrm{AlCl}_{2}\right)^{+}$, and $\left(\mathrm{BCl}_{2}\right)^{+}$. The electron clouds of acid sites on Cat. II and Cat. III transfer to other parts, resulting in significant reduction in the activity of the modified catalyst. The results of the energy analysis are consistent with the results of the previous catalyst structure analysis (Table 1).

To further validate the above-mentioned inference, we performed LOL analysis, as shown in Figure 6. The locality of active site of Al$\mathrm{Cl}$ (circled by the dotted line) from the strong to the weak is: Cat. I > Cat. II > Cat. III. However, the figure shows that in Cat. I the $\mathrm{Cl}$ of $\mathrm{Al}-\mathrm{Cl}$ is easiest to give delocalized electrons. The delocalized electrons of Cat. III concentrate on the unreactive $\mathrm{Al}$ atom, and Cat. II is centered. So the order of catalytic activity is Cat. I > Cat. II > Cat. III. This is also consistent with the calculation of the activation energy. The results of LOL analysis are consistent with the results
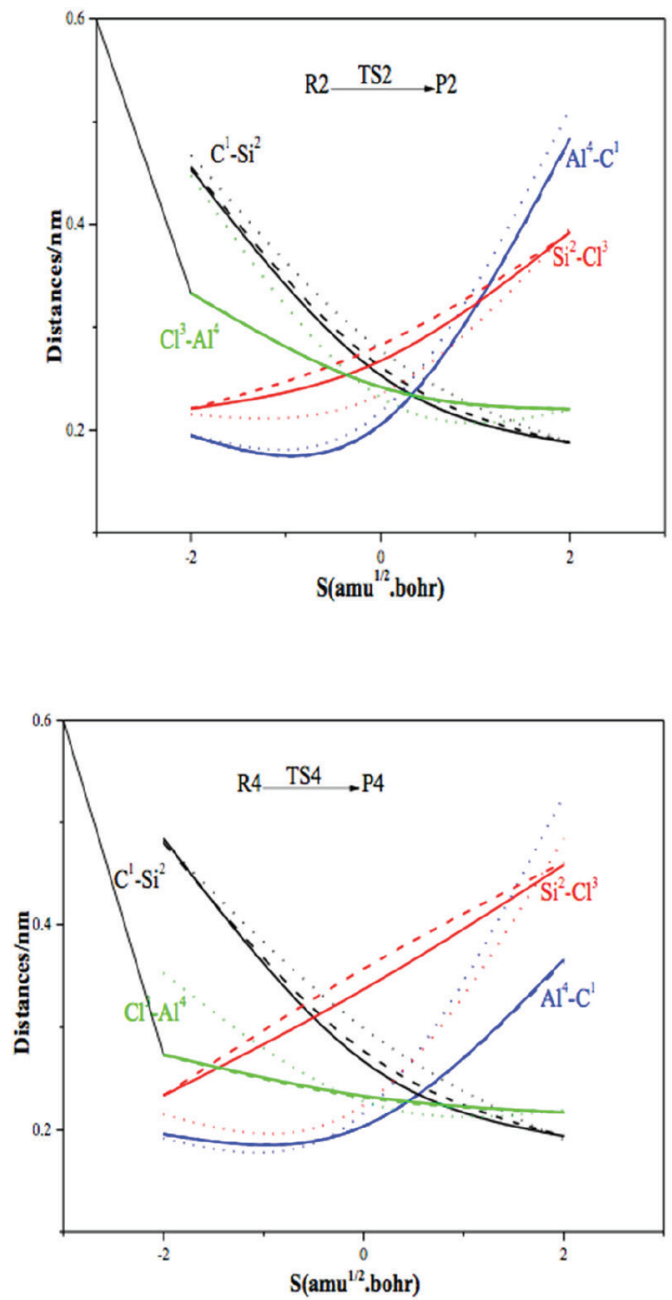

Figure 3. The spacing trends of key atoms along IRC in the system (…Cat.I, ---Cat.II, -Cat.III) 

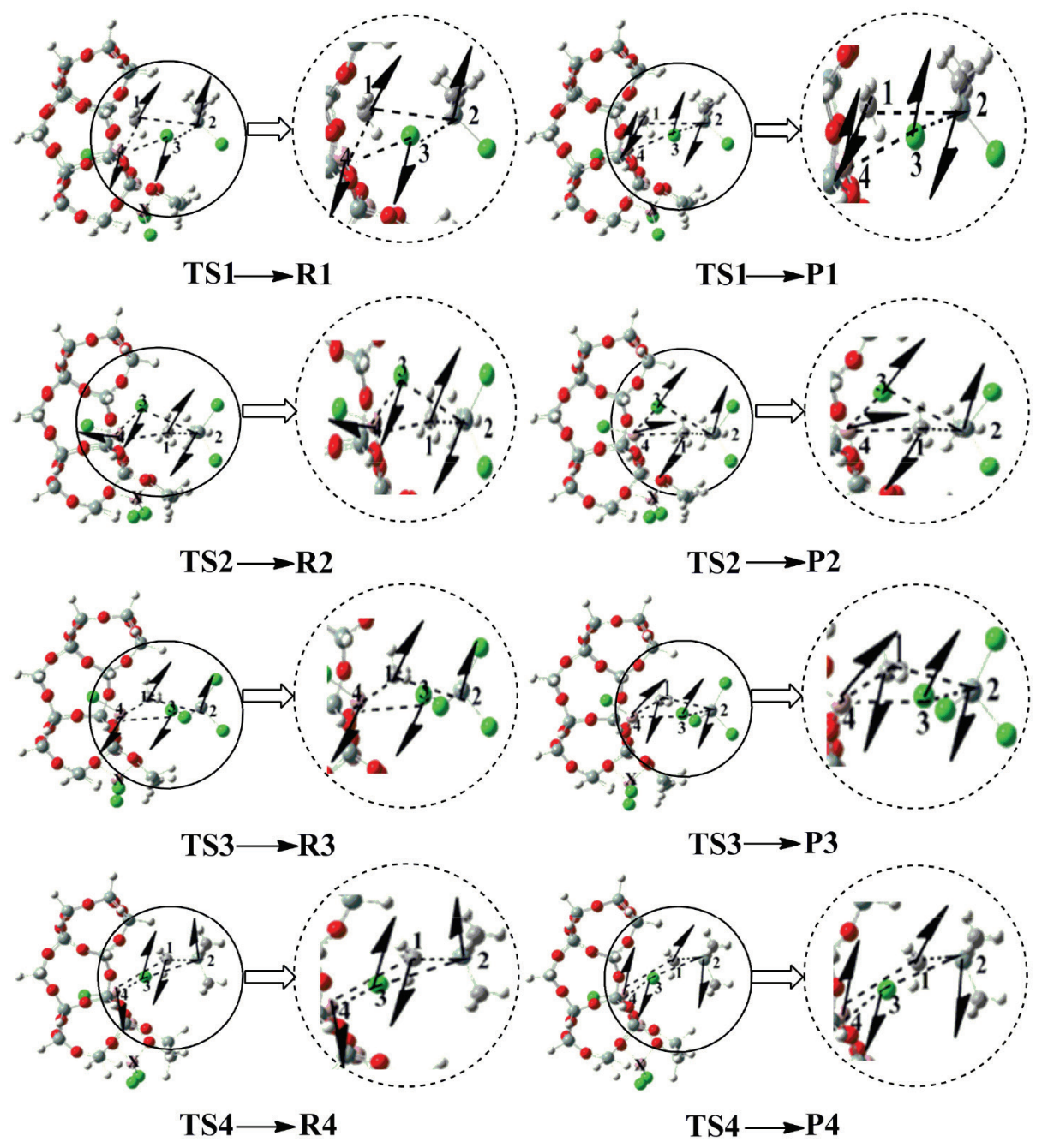

Figure 4. The vibration modes of transition states in catalytic process of $\mathrm{AlCl}_{3} / \mathrm{X}-\mathrm{ZSM}-5$ catalyst

Table 2. Reaction enthalpies and Activation energies of $\mathrm{AlCl}_{3} / \mathrm{X}-\mathrm{ZSM}-5$ catalyst

\begin{tabular}{|c|c|c|c|c|}
\hline & & $\mathrm{AlCl}_{3} / \mathrm{ZSM}-5$ & $\mathrm{AlCl}_{3} /\left(\mathrm{AlCl}_{2}\right)^{+}-\mathrm{ZSM}-5$ & $\mathrm{AlCl}_{3} /\left(\mathrm{BCl}_{2}\right)^{+}-\mathrm{ZSM}-5$ \\
\hline \multirow[t]{4}{*}{ Reaction enthalpies $\left(\mathrm{kJ} \mathrm{mol}^{-1}\right)$} & $\Delta \mathrm{H}_{1}$ & 76.13 & -479.28 & 204.79 \\
\hline & $\Delta \mathrm{H}_{2}$ & -75.10 & 56.30 & -78.77 \\
\hline & $\Delta \mathrm{H}_{3}$ & -463.82 & -276.99 & -384.90 \\
\hline & $\Delta \mathrm{H}_{4}$ & -21.30 & 118.15 & -284.40 \\
\hline \multirow[t]{4}{*}{ Activation energies $\left(\mathrm{kJ} \mathrm{mol}^{-1}\right)$} & $\mathrm{E}_{\mathrm{a} 1}$ & 393.83 & 427.73 & 527.61 \\
\hline & $\mathrm{E}_{\mathrm{a} 2}$ & 304.56 & 387.52 & 403.87 \\
\hline & $\mathrm{E}_{\mathrm{a} 3}$ & 461.43 & 297.73 & 400.13 \\
\hline & $\mathrm{E}_{\mathrm{a} 4}$ & 422.80 & 483.62 & 429.01 \\
\hline
\end{tabular}

of the previous catalyst structure analysis (Table 1) and activation energy analysis (Figure 5 and Table 2).

\section{CONCLUSIONS}

MP2/6-311++G (3df, 2pd) basis set was employed to study the mechanism of the disproportionation of dichlorodimethylsilane, which was catalyzed by a $24 \mathrm{~T}$ cluster $\mathrm{AlCl}_{3} / \mathrm{ZSM}-5$ pre- and postmodified by $\left(\mathrm{AlCl}_{2}\right)^{+}$, and $\left(\mathrm{BCl}_{2}\right)^{+}$. The conclusions are summarized as below:

(1) In the main reaction, the activation energy of the rate-determining step is: $393.83,427.73$, and $527.61 \mathrm{~kJ} \mathrm{~mol}^{-1}$, respectively. Comparing with the $5 \mathrm{~T}$ cluster $\mathrm{AlCl}_{3} / \mathrm{ZSM}-5\left(93 \mathrm{~kJ} \mathrm{~mol}^{-}\right.$ ${ }^{1}$ ), we find that $5 \mathrm{~T}$ cluster is better. Indicating that the main activity of the disproportionation reaction is on the surface of the catalyst.

(2) The order of catalyst activation energy ranks as $\mathrm{AlCl}_{3}$ / ZSM-5 > $\mathrm{AlCl}_{3} /\left(\mathrm{AlCl}_{2}\right)^{+}-\mathrm{ZSM}-5>\mathrm{AlCl}_{3} /\left(\mathrm{BCl}_{2}\right)^{+}-\mathrm{ZSM}-5$. Further $\mathrm{LOL}$, analysis are consistent with the activation energy conclusions.

(3) The vibration analysis of the transition states and IRC calculation show that the reaction mechanism is credible. The results of catalyst structure analysis and energy analysis are consistent with LOL analysis. 


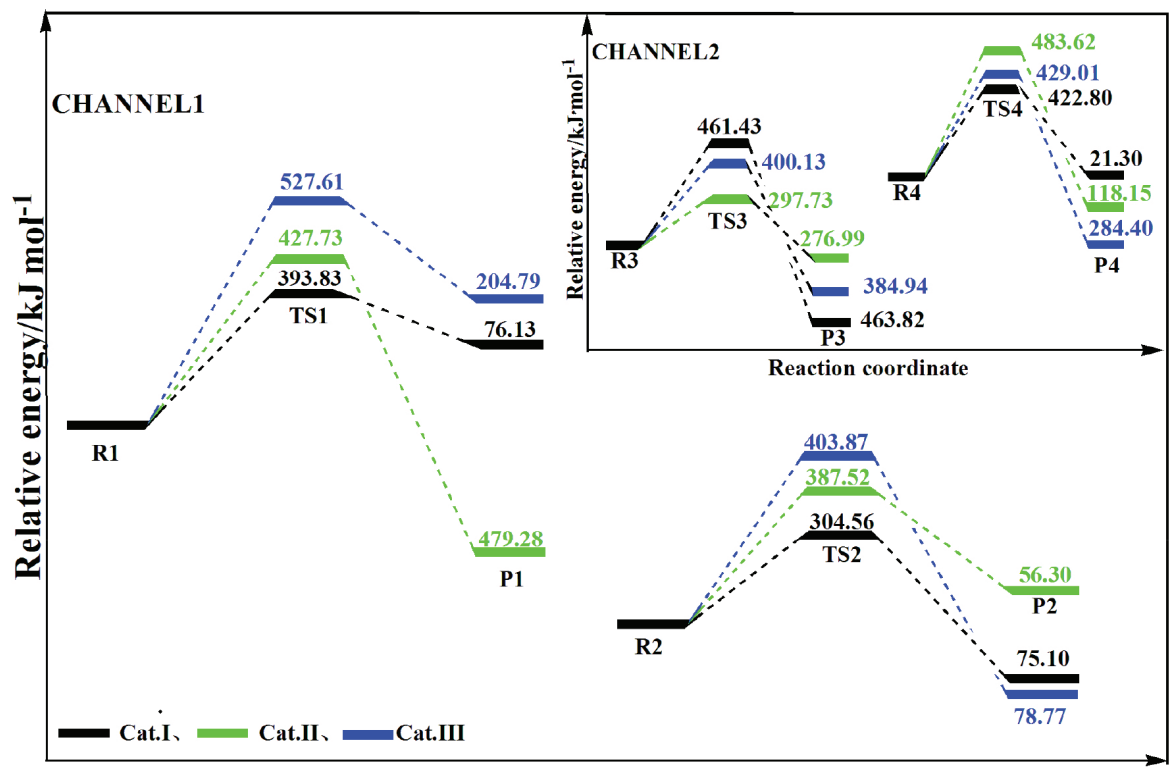

Reaction coordinate

Figure 5. Curves of IRC pathways in catalytic system by $\mathrm{AlCl}_{3} / X-Z S M-5$ catalyst
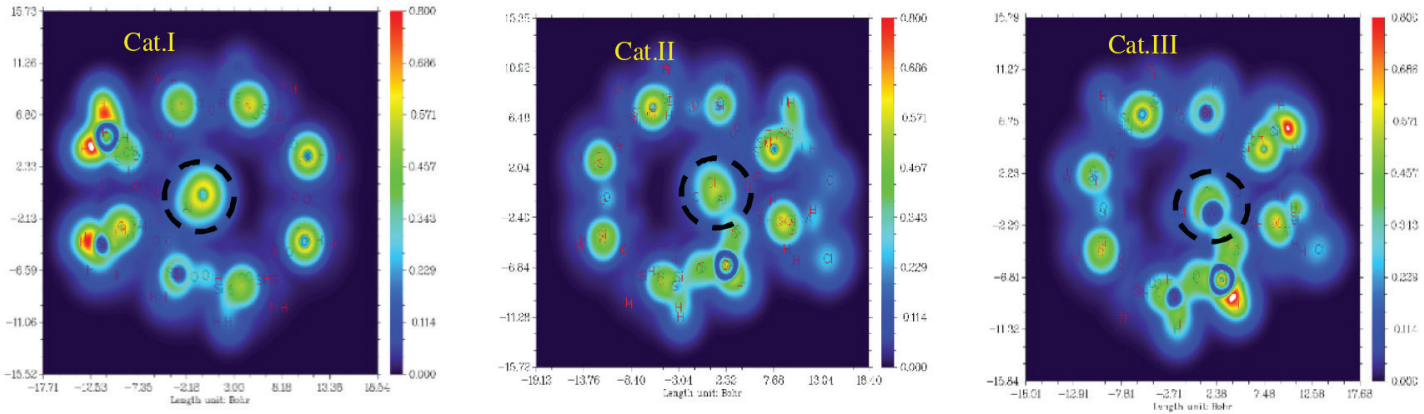

Figure 6. LOL analysis of different catalysts

\section{ACKNOWLEDGEMENTS}

The authors thank the National Science Foundation of China (No. 21563011) for supporting this work.

\section{REFERENCES}

1. Wu, S. J.; Organic silicon application, $4^{\text {th }}$ ed., University of Electronic Science and Technology: Cheng Du, 2000.

2. Li, H. T.; Silicone Mater. 2006, 20, 212.

3. Camel, D.; Drevet, B.; Eustathopoulos, N.; J. Mater. Sci. 2016, 51, 1722.

4. Zou, S. Y.; Ji, Y. J.; Li, J.; Zhang, Y.; Jin, Z.Y.; Jia, L. H.; Guo, X. F.; Zhong, Z. Y.; Su, F. B.; J. Catal. 2016, 337, 1.

5. Pakizeh, M.; Moghadam, A. N.; Omidkhah, M. R.; Namvar-Mahboub, M.; Kor. J. Chem. Eng. 2013, 30, 751.

6. Schweizer, J. I.; Meyer, L.; Nadj, A.; Diefenbach, M.; Holthausen, M. C.; Chem. Eur. J. 2016, 22, 14328.

7. Xue, J. G.; Long, J. F.; Gong, S. X.; Shi, H. B.; Feng, C. X.; Silicone Mater. 2000, 14, 20.

8. Zhao, J. B; Zhang, N.; Ind. Catal. 2003, 11, 37.

9. Liu, G. Q.; Cui, B.; Xu, R.; Li, Y. M.; J. Org. Chem. 2016, 81, 5144.

10. Yang, Y. Y.; Liu, H. X.; Peng, C.; Wu, J.; Zhang, J. Y.; Qiao, Y.; Wang, X. N.; Chang, J. B.; Org. Lett. 2016, 18, 5022.

11. Zhao, Y.; Yang, Z.; Tang, L.; Chin. J. Org. Chem. 2003, 23, 1219.

12. Yin, D. H.; Li, C. Z.; Tao, L.; Yu, N. Y.; Hu, S.; Yin, D. L.; J. Mol. Catal. A: Chem. 2006, 245, 260.

13. Blair, R. G.; Gillan, E. G.; Nguyen, N. K. B.; Daurio, D.; Kaner, R. B.;
Chem. Mater. 2003, 15, 3286.

14. Geeta Pamar, M.; Govender, P.; Pillay, K.; Abrahamse, H.; Nanjundaswamy, H. M.; Indian J. Chem. 2015, 54B, 110.

15. Dong, W. G.; Liu, Y. F.; Xu, C. M.; Petrochem. Technol. 2002, 31, 85.

16. Herbert, L. W.; US pat: 6,013,824 2000.

17. Shao, Y. G.; Master Dissertation, Zhejiang University, China, 2004.

18. Xu, W. Y.; Wan, H. H.; Wang, L. W.; Hong, S. G.; Asian J. Chem. 2016, $28,1624$.

19. Xu, W. Y.; Yao, C. J.; Xu, Y. C.; Hong, S. G.; Asian J. Chem. 2017, 29 , 104.

20. Fellah, M.; Onal, I.; J. Phys. Chem. C 2010, 114, 3042.

21. Shinya, H.; Masaya, M.; Hiromi Y.; Masakazu A.; J. Phys. Chem. B 2000, 104, 10288.

22. Xie, H. J.; Wang, J. W.; Feng, Y. L.; J. Mol. Catal. 2000, 14, 289.

23. Sakatani, Y. H.; Uehara, S. Z.; Kentaroh, Y. S. D.; J. High Energy Phys. 2017, $2017,1$.

24. Mahboobeh, G.; Sayyed, F. T.; Saeedreza, E.; Can. J. Chem. 2016, 94 , 818.

25. Burgera, S. K.; Ayers, P. W.; J. Chem. Phys. 2010, 132, 234110-1.

26. Ionova, I. V.; Carter, E. A.; J. Chem. Phys. 1995, 103, 5437.

27. Jiang, X. N.; Wang, C. S.; Sci. China: Chem. 2010, 53, 1754.

28. Heiko, J.; Can. J. Chem. 2009, 87, 965.

29. Heiko, J.; Can. J. Chem. 2008, 86, 695.

30. Yu, H. S.; Fiedler, L. J.; Alecu, I. M.; Truhlar, D. G.; Comput. Phys. Commun. 2017, 210, 132.

31. Khafizov, N. R.; Madzhidov, T. I.; Kadkin, O. N.; Tamura, R.; Antipin, I. S.; Int. J. Quantum Chem. 2016, 116, 1064. 
32. Dhamodharan, P.; Sathya, K.; Dhandapani, M.; J. Mol. Struct. 2017, 1146, 782 .

33. Wang, B. B.; Yi, H.; Xu, K. L.; Wang, Q. S.; J. Therm. Anal. Calorim. 2017, 128, 399.
34. Lear, S.; Cobb, S. L.; J. Comput. Aided Mol. Des. 2016, 30, 271.

35. Morsch, L. A.; Lewis, M.; J. Chem. Educ. 2015, 92, 1402.

36. Evans, D. A.; Angew. Chem., Int. Ed. 2014, 53, 11140. 